\title{
Relationship Between Radiologic Morphology of the Bone Lengthening Formation and Its Complications
}

Francisco Forriol, M.D., ${ }^{*}$ Alfonso Iglesias, M.D., $\dagger$ Mercedes Arias, M.D., $\dagger$ Damaso Aquerreta, M.D., $\uparrow$ and Jose Cañadell, M.D.*

Departments of *Orthopaedic Surgery and Traumatology and †Radiology, Clínica Universitaria, School of Medicine, University of Navarra, Pamplona, Spain

Address correspondence and reprint requests to Dr. Francisco Forriol, Department of Orthopaedic Surgery, Clínica Universitaria, University of Navarra, 31080 Pamplona, Spain.

\section{SUMMARY}

The objective was to study the different types of lengthened bone regeneration and their development during the various phases of the process to correlate them with patient factors and the surgical technique used, and to establish a possible relation between the development of the bone lengthening formation and the problems or complications. The authors studied the radiographs of a random group of 55 patients taken at three points during the course of treatment. The callus was classified with regard to its transverse diameter and the presence or absence of hypodense areas. The overall callus type was significantly influenced by the etiology, the osteotomy site, and the percentage lengthened. The percentage by which the limb was lengthened at the beginning of the process influences the overall morphology of the callus. Poor callus had been lengthened the most, atrophic callus the least. There was a correlation between the morphology of the overall callus at the end of treatment and the percentage lengthened, and between the percentage lengthened and the presence of bands at the end of treatment. The authors also found a significant correlation between age and the appearance of bands at the end of distraction. A central band was found among younger patients. The type of osteotomy affected the overall callus at the end of distraction and at the end of treatment and also influenced the transverse diameter. All the elongations with poor bone formation at the end of treatment were found to have undergone a diaphyseal osteotomy. The most common complication at the first follow-up and at the end of distraction was angulation. The diameter of the callus and the presence of bands at the end of treatment were significantly related to the complications. Fracture occurred in the first 2 weeks after removal of the external fixator in $88 \%$ of cases and in the third and fourth week in the rest. However, the segment had no significant influence on the appearance of complications. Lengthened callus with incomplete trabecular formations and hypodense areas at the end of the treatment has a high risk of fracture at the end of treatment. Callus with axial deviation, hypodense areas, or an insufficient transverse diameter during the lengthening procedure must be manipulated so that it reaches the maturing phase in better condition.

\section{KEY WORDS}

Bone lengthening; Bone formation; Complications; External fixation. 


\section{INTRODUCTION}

Progressive bone lengthening is a technique that requires careful patient follow-up to track the development of the lengthening neoformation and to prevent complications. It is therefore important to schedule periodic clinical examinations, complemented by precise follow-up using diagnostic imaging techniques, and also to learn how to interpret the morphologic development of the bone lengthening callus formation.

During the lengthening process, different radiologic images of the regenerated bone are found. This leads the authors to believe that there may be a relation between the morphology and the development of the lengthening callus, taking into account patient factors and the characteristics of the technique used. Complications constitute a large chapter in the literature on bone lengthening; however, there are no uniform criteria for defining the term "complications" or for classifying them. As a result, the complication rate varies from $3 \%$ to $236 \%$, based on the criteria applied $(4-7,10,11,22,24)$.

The aim of the present study is to draw up a morphologic classification of the types of lengthened callus and to study their development during the process to correlate them with patient factors and the surgical technique used and to establish a possible relation between the development of the bone lengthening formation and the complications that may later arise in the lengthened callus.

\section{METHODS}

A random group of 55 patients was analyzed, all of whom had undergone bone lengthening by progressive bone distraction after a percutaneous osteotomy using a monolateral external fixator (Table 1). The radiographs taken at three points during treatment were examined: at the first examination after surgery, at the end of distraction, and at the end of treatment once the fixator or splint was removed. At these three points, the callus was classified with regard to its transverse diameter and the presence or absence of hypodense areas.

The transverse diameter (Fig. 1) can be classified as major (broader than the original bone); similar or homogenous (same width as the original bone); or poor or narrower (less than one third of the original bone). The "C" callus is a defective ossification at the edge closest to the fixator. The formation of the bone is on the side opposite the fixator. The atrophic calcus is when the isolated ossifications are without bone formation. The classification of hypodense areas or bands depends on their location in the bone formation: central, proximal, or distal (Fig. 2).

In each lengthening process, the following factors were analyzed:

- Intrinsic factors: sex, age of surgery, etiology (symmetric or bilateral short stature; asymmetric or unilateral short stature), and lengthened segment

- Technical factors: site of osteotomy (proximal metaphyseal, diaphyseal, distal metaphyseal) and percentage lengthened

The intrinsic and the technical factors were correlated with the complications that occurred (premature consolidation, delayed consolidation, fracture, angulation) in the 
three phases of the study, and these were in turn correlated with the overall morphology of the callus, its transverse diameter, and the radiologic hypodense areas.

A descriptive statistical study was performed, as was analysis of the interdependence of variables, both at the beginning and at the end of distraction and maturation. The differences in quantitative variables between groups were studied by variance analysis, and comparative tests were subsequently performed (Scheffe, Dunnett, and Fisher tests were used). The relations between continuous quantitative variables were analyzed by regression studies. The qualitative variables studied by bivariant analysis were assessed by chi square distribution. In all studies, $\mathrm{P}<0.05$ was taken as being significant, $\mathrm{P}<0.01$ as highly significant.

\section{RESULTS}

Overall analysis of the types of bone formation, focusing on transverse diameter and hypodense areas, showed that the most common kind of callus was the "similar/no band" at the beginning of the lengthening process and "similar/with central band" at the end of distraction; at the end of treatment, approximately $60 \%$ of cases were "similar/no band" (Table 2). Similar callus (callus with the same transverse diameter as the neighboring bone) was the most common type of callus in all phases of treatment. Its frequency increased from the first examination $(47.62 \%)$ to the end of treatment $(86.32 \%)$. Type " $\mathrm{C}$ " callus was the second most common kind of callus found at the first examination, but the percentage of "C" callus fell as the process went on. This was also the case with atrophic callus, which was the third most common kind found. At the end of distraction, the authors counted 10 instances of atrophic callus, 7 of which were subjected to further surgery; the other 3 progressed correctly. The incidence of poor callus increased slightly from the first examination to the end of distraction, although it then fell at the end of treatment (Table 3).

At the end of distraction, the number of cases of callus with no band fell, and the number with a central band increased. At the end of treatment, the number of cases of callus with no band increased, and the number with a central band fell (see Table 3).

The overall callus type was significantly influenced by the etiology, the osteotomy site, and the percentage lengthened. The transverse diameter of the callus was significantly influenced by the etiology, the osteotomy site, and the percentage lengthened. The etiology and the percentage length increase had a significant influence on the appearance of bands. Neither gender nor age influenced the radiologic morphology of the overall regenerates in any of the three phases of the study. Nonetheless, a higher age was found among the cases of atrophic callus, whereas similar and " $\mathrm{C}$ " callus had a similar mean age, and the greater and poor callus types were found to have a lower mean age than the others at this point in the study (Table 4).

Distal bands were associated with a greater percentage length increase $(62.1 \%)$. The absence of bands corresponded to a $52.3 \%$ increase, and the presence of central and proximal bands correlated with similar figures of $33.6 \%$ and $30 \%$, respectively. The authors also found a significant correlation between age and the appearance of bands at the end of distraction: bilateral (proximal and distal) bands appeared in the older group (mean age, 18 years). A central band was found among younger patients (mean age, 
10.9 years). In contrast, an average age of 13 years was found in the patients with no bands, and the ages at which distal and simultaneous central and distal bands appeared were 12 years and 12.2 years, respectively (see Table 4 ).

Etiology influenced the diameter of the callus at the start of the process and at the end of distraction but not at the end of treatment. The greatest percentage of well-formed callus was found in dysplastic patients (greater and similar types), whereas the greatest percentage of atrophic callus was detected in patients with congenital short stature. Patients with a nondysplastic etiology followed a homogeneous course: one third produce normal callus, another third produce reduced callus (" $\mathrm{C}$ " and poor), and the remaining third have atrophic callus. More than $50 \%$ of patients with a noncongenital etiology were found to have type " $\mathrm{C}$ " callus. Central bands appeared most frequently in patients with dysymmetric short stature; in symmetric patients, bands mostly disappeared by the end of treatment.

The percentage by which the limb was lengthened at the beginning of the process influenced the overall morphology of the callus $(\mathrm{P}=0.0003)$. Poor callus had been lengthened the most, atrophic callus the least. There was a correlation between the morphology of the overall callus at the end of treatment and the percentage lengthened $(\mathrm{P}=0.0024)$ and between the percentage lengthened and the presence of bands at the end of treatment $(\mathrm{P}=0.003)$.

The type of osteotomy affected the overall callus at the end of distraction $(\mathrm{P}=0.005)$ and at the end of treatment $(\mathrm{P}=0.0023)$ and also influenced the transverse diameter, although it had no effect on the presence of bands in any of the three phases of the study. At the end of treatment, the most frequent type of bone formation was the similar kind, which was present in $>85 \%$ of patients with metaphyseal osteotomies. In the case of diaphyseal osteotomy, similar callus accounted for $67 \%$ of segments, and poor callus $(19 \%)$ was the second most common kind. All the limbs with poor callus at the end of treatment were found to have undergone a diaphyseal osteotomy (Table 5).

It is normal for no callus complications to arise in any of the three phases of the process. The most common complication at the first examination is angulation. The authors also observed two cases of premature consolidation, which required surgical treatment. At the end of distraction, too, angulation was the most frequent complication. The authors observed 12 cases of delayed consolidation. At the end of treatment, the most common complication was fracture (Table 6). Regarding the overall morphology of the regenerate, the authors found a significant correlation $(\mathrm{P}=0.014)$ with the complications detected at the first examination: angulation was more frequent in callus with a central hypodense area.

The diameter of the callus at the end of treatment was significantly related to the complications $(\mathrm{P}=0.0001)$. Poor callus fractured in all cases, whereas two of the five cases of "C" callus fractured (40\%). Well-formed callus (major and similar) proved less likely to fracture (14.2\% and $18.8 \%$, respectively) (see Table 6$)$.

At the end of distraction, the atrophic callus was found to have the greatest percentage of delayed consolidation, whereas " $\mathrm{C}$ " callus was the kind most prone to angulation. At the end of treatment, it was the major callus without a band that presented no complications. Of the four cases with a central band, one fractured and another 
underwent angulation. Even callus without a band proved the most frequent kind (69 cases), out of which only one case fractured and four suffered angulation. The authors found 21 examples of lengthened callus that were even with a central band at the end of treatment, out of which 13 fractured $(61.9 \%)$. Of the 11 cases of similar callus with bands at the extremes, $5(45.4 \%)$ fractured. The authors found four examples of "C" callus with no band, of which one fractured and two underwent angulation. There was only one " $\mathrm{C}$ " callus with a central band that fractured. Of the four cases of poor callus without a band observed at the end of treatment, all fractured.

The presence of bands in the callus at the end of treatment influenced the complication rate. The callus with a central band fractured in $57 \%$ of cases. Of the nine cases with a band at the distal extreme, five fractured (55.5\%). The fracture occurred in the first 2 weeks after removal of the external fixator in $88 \%$ of cases and in the third and fourth week in the rest. Although the segment had no significant influence on the appearance of complications, of the 12 cases of delayed consolidation observed at the end of distraction, 11 were in the tibia. In the cases of fracture at the end of treatment, 16 occurred in the femur, 9 in the tibia, and 1 in the humerus.

Neither sex, nor the site of the osteotomy, nor the percentage lengthened influenced the complication rate in any of the three phases of the study. Nor did the authors find that age had any bearing on the complications at the start of the process or the end of treatment, although delayed consolidation occurred in older patients (mean age, 16 years); the patients in whom the authors observed no complications had an average age of 11.9 years, whereas those who suffered angulation had an average age of 13 years.

The etiology influenced the complications observed at the end of distraction $(P=0.03)$ : the incidence of angulation was greater in patients with asymmetric short stature and delayed consolidation was more frequent in nondysplastic patients (e.g., Turner, premature puberty).

\section{DISCUSSION}

Bone lengthening formation follows a homogeneous process from the very beginning. At the first examination, modifications in the callus can be observed that lead to a state of maturation in its transverse diameter and mineralization. A straightforward radiologic study has always been the preferred method for monitoring the course of osteogenesis during lengthening processes: it is quick, readily available, and low in cost. It is also the imaging technique that provides the greatest amount of information, both about the focus of lengthening and about the areas of fixation and the adjacent joints; this makes it the ideal method for detecting the problems and forestalling the complications that may ensue during the lengthening process. It has the drawback that it uses ionizing radiation, and therefore various radioprotection measures must be applied.

During the distraction phase, examinations are normally conducted every month if no abnormalities are detected. During maturation and until the fixator is removed, they are held every 2 months. Visits are subsequently scheduled 2, 6, and 12 months after the removal of the fixator to confirm that the remodeled bone has developed correctly. 
Many attempts have been made to classify lengthened callus using radiography. Hamanishi et al. (9) paid special attention to the transverse diameter, describing six types of callus: external or hypertrophic; straight or homogenous; poor, narrower than the original bone; opposite formation of bone on the side opposite the fixator; columnar or linear; and central and agenesic. Cañadell et al. (4) classified three types of callus: callus that completely fills the gap, " $\mathrm{C}$ " callus, and callus with sparse, disorganized trabeculation. Bowen et al. (3) distinguished four types of callus: minimal, with cystic areas; biconcave; of similar diameter to the original bone; and of greater diameter than the original bone.

In this study, the authors selected three points during the course of the process with a view to assessing the bone formation. The first was 6 weeks after the start of distraction, the second at the end of distraction, and the third before the removal of the fixator. Ossified trabeculae inside the callus mainly appeared at the ends, and continuity was broken in $72.2 \%$, which meant that the callus often did not present as bands or defective zones in the center. The two ossification fronts advanced from the ends of the bone, with fusion taking place in the central area and the trabeculae lining up lengthways with the lines along which the forces were being transmitted, and the callus gradually filling up.

The examination at the end of distraction showed that the most common type of callus was the one described as similar, with a central band. In other words, the percentage of bone regenerate with a similar diameter increased with respect to the first examination, whereas the number of cases of atrophic callus dwindled. In $80 \%$ of cases there was union between the two fronts of ossification, but the percentage with a central gap increased.

The maturation phase is a period of waiting until the focus of lengthening consolidates completely. The density of the callus gradually increases, and in time a fine cortex appears that slowly increases in thickness as the differentiation between the callus and the rest of the bone lessens. A landmark in this phase is the removal of the fixator at the point when the bone formation is assumed to be sufficiently mature to allow walking without the risk of fracture. Clinical and radiologic criteria should be taken into account when making the decision to remove the fixator, including the state of maturation of the bone callus, the length of time since the fixator was put into position, and the state of the filling, which should be complete, without defective mineralization. The radiologic study must assess the diameter and the presence of possible defects of mineralization at the time the fixator is removed, because callus with a reduced diameter (poor and "C") or defective mineralization is associated with an increased risk of fracture.

Age plays an important part in bone lengthening, and there are obvious differences between children and adults. Paley (22) set the age limit for performing lengthening with a guarantee of success at 20 years. Young et al. (26) believed that age influences the formation of new bone, because lengthening performed in patients older than 19 is associated with delayed consolidation. Vade and Eissenstat (24) wrote that the best age for starting lengthening is between 15 and 16 years; they believed that in this age group bone regeneration is as good as in children, and there is good motivation. In this study, age was found to influence the diameter of the callus at the end of distraction. The mean age in cases of atrophic callus was 17.6 years, much greater than that in the other types of callus; similar callus had a mean age of 12.7 years. At the end of treatment, the mean 
age among patients with poor callus was 5 years, much lower than that in any other callus group at this point. In other words, at the end of distraction, the mean age of patients with atrophic callus is much higher, whereas at the end of treatment the patients with poor callus belong to the youngest age group.

The radiologic hypodense areas that appear in the callus are also age-related. At the end of distraction, bands at the extremes of the callus appear in the oldest patients (mean age, 18 years), whereas bands in the center of the callus can be observed in younger patients (mean age, 10.9 years). The hypodense area in the center of the callus corresponds to a delay in the union of the trabeculae of the proximal and distal segment.

Patients were classified into two groups according to the cause of their shortnesssymmetric (bilateral lengthening) or asymmetric (unilateral lengthening). The symmetric patients were divided into two groups, the largest of which consisted of patients whose shortening was of dysplastic origin; within this group, most patients were achondroplastic. The largest percentage of normal (major and similar) callus was observed among dysplastic patients. At the end of treatment, it was this group that had the smallest percentage of bands inside the callus. However, the authors noted that poor callus at the end of treatment was found in achondroplastic patients, as Hamanishi et al. (9) observed. The other group with symmetric shortness included those of nondysplastic origin (hormonal [premature puberty, hypothyroidism], chromosomal [Turnen], and idiopathic); this group had the largest percentage of atrophic callus at the end of distraction.

Patients with asymmetric shortening were classified into two groups, congenital and noncongenital. In the congenital group, at the end of distraction $>50 \%$ had reduced callus (poor and "C"); this was the group with the lowest percentage of normal callus at the end of distraction. In the other group, comprising unilateral short stature of noncongenital origin (traumatic or infectious), at the start of the process $>50 \%$ had " $\mathrm{C}$ " callus, and there was no atrophic callus. These progressed well, and at the end of distraction $71.5 \%$ of segments had normal callus. At the end of treatment, one third of the congenital patients had a central band, compared with two thirds of the noncongenital patients.

The osteotomy should be performed in the least traumatic way possible, with conservation of the periosteum, medullary vascularization, and soft tissues: these are important factors in the formation of high-quality callus, as has been shown in various experimental and clinical reports $(1,2,6,12,14,16,17,19,23,25)$. The site of the osteotomy also influences callus formation. Fewer complications were observed when the osteotomy was metaphyseal $(1,4,7,9,13,15-18)$; this seems to be related to the presence of spongy bone, which consolidates easily; the existence of fewer muscular insertions; and the fact that less damage is done to the vascularization, particularly the medullary artery, which is highly ramified at this point. The latter has been demonstrated by angiographic studies $(2,15)$, which show that diaphyseal corticotomy interrupts the endomedullary vessels in $90 \%$ of cases.

In this study, the osteotomy site influenced the diameter of the callus. When a metaphyseal osteotomy was performed, the diameter was normal (similar or major) at the end of treatment in $92 \%$ of cases, whereas with diaphyseal osteotomy only $76 \%$ were normal and $20 \%$ had poor callus. It was found that all the instances of poor callus 
at the end of treatment had occurred in cases where the osteotomy was diaphyseal, and all fractured, which confirms observations made in previous studies that also noted a high percentage of fractures after diaphyseal osteotomy (7,20-21).

The smallest length increases found in this study were associated with atrophic callus, although the other factors mentioned above, such as age and etiology, should be taken into account when seeking an explanation for this type of callus. The greatest percentage increase corresponded to poor callus.

When examining the appearance or absence of bands and the position in which they occur, it can be seen that the greater the bone lengthening percentage, the greater the possibility of finding hypodense areas; this is shown by the fact that at the end of treatment, such areas are found only in symmetric patients, whereas gaps in the center may be affected by etiology, because they are more common in asymmetric patients. Bone regenerate without a band was found to correlate with a greater percentage length increase than callus with a central band, probably because the central band reflects slow maturation of the callus.

Angulation is the most common complication at the first examination and at the end of distraction. Deviation usually follows one characteristic direction, depending on the bone affected and the site of the osteotomy. Thus, proximal femoral osteotomies tend to deviate in varus, whereas those performed on the tibia follow a valgus pattern (22). These deviations have been explained by the imbalance between the muscular tractions in the respective bone segments, because they occur with both monolateral and circular fixators $(5,8,19,22)$. Axial deviations can cause disorders of the articular loading axil; depending on the degree of deformity that results, corrective osteotomies may be necessary.

The number of angulations found at the end of treatment was lower than that encountered in the two earlier phases, because cases of this kind were corrected during the process by manipulation of the lengthening focus. " $\mathrm{C}$ " callus was the most frequently associated with angulation.

Only two instances of premature consolidation were observed, both in achondroplastic patients. This may occur secondary to incomplete osteotomy, to a delay in the start of distraction after osteotomy, to an excessively slow rate of lengthening, or to accelerated maturation, for which reason the authors recommend that a large intraoperative distraction of $5 \mathrm{~mm}$ should be performed to ensure the osteotomy is complete. Maffulli et al. (18) proposed that ultrasound should be used to ensure that the osteotomy is complete, with a view to preventing premature consolidation.

Delayed consolidation was taken to mean callus that was atrophic at the end of distraction, or cases that required a graft or osteosynthesis material to continue the lengthening process. Delayed consolidation was most frequent in old patients (average 16 years) and in symmetric shortening of nondysplastic origin $(21.43 \%)$; it occurred in only $5.5 \%$ of dysplastic patients.

If consolidation is delayed, the rate of distraction of the segment must be adjusted (26) or an accordion maneuver performed. When the consolidation of the focus is not 
achieved, intraoperative bone grafts are undertaken, and in some cases osteosynthesis material is inserted.

Use of an interlocking nail immediately after the desired length is reached may be a good solution for delays in consolidation in young patients who do not walk or maintain their normal day-to-day activities.

All the cases of poor callus fractured after the fixator was removed. Of five instances of "C" callus, two fractured. Regarding normal callus, one major callus with a central band fractured; among the cases of even callus, $57.6 \%$ of those with a central band and $55.5 \%$ of those with a band at the distal extreme fractured. This indicates that the fractures observed at the end of treatment occurred after the premature removal of the fixator in the case of a callus that had not matured sufficiently to bear weight. The radiologic absence of a complete cortex on both sides of the lengthened bone regenerate with trabecular lines forming a bridge between both ends of the bone lengthening formation is associated with a high risk of fracture $(4,24)$.

The shape of the lengthened bone formation should serve as a warning about possible complications. Lengthened callus with incomplete trabecular formations (" $\mathrm{C}$ " or poor callus) and hypodense areas (central or distal extreme band) at the end of treatment has a high risk of fracture, particularly in the first 2 weeks after the fixator is removed, even where splints are used. Callus with axial deviation, hypodense areas, or an insufficient transverse diameter during the lengthening procedure must be manipulated so that it reaches the maturing phase in a better condition.

\section{REFERENCES}

1. Aronson J, Good B, Stewart CH, Harrison B, Harp J. Preliminary studies of mineralization during distraction osteogenesis. Clin Orthop 1990;250:43-9.

2. Arrien A. Estudio comparativo de las osteotomías a cielo abierto y percutáneas en la elongación ósea. Doctoral dissertation, Navarra University, 1986.

3. Bowen JR, Levy EJ, Donohue M. Comparison of knee motion and callus formation in femoral lengthening with the Wagner or mono-lateral-ring device. J Pediatr Orthop 1993;13:467-72.

4. Cañadell J, Aquerreta D, Forriol F. Prospective study of bone lengthening. J Pediatr Orthop Part B, 1993;2:1-7.

5. Cañadell J. Bone lengthening: clinical experience. In: Postgraduate Lectures (EFORT), 1st Congress of Orthopaedics, Masson, Paris, 1993:129-34.

6. Dutoit M, Rigault P, Padovani JP, Finidori G, Touzet P, Durand Y. Le devenir des enfants opérés d'allongement pour hypoplasie congénitale des membres inférieurs. Rev Chir Orthop 1991;76:1-7.

7. Faber FW, Keessen W, Van Roermund PM. Complications of leg lengthening. 46 procedures in 28 patients. Acta Orthop Scand 1991;62:327-32.

8. García E, Olsen B, Ruiz M, Fernández N, Munuera L. Ilizarov technique. Results and difficulties. Clin Orthop 1992;283:116-23.

9. Hamanishi C, Yasuwaki Y, Kikuchi H, Tanaka S, Tamura K. Classification of the callus in limb lengthening. Radiographic study of 35 limbs. Acta Orthop Scand 1992;63:430-3. 
10. Herzog R, Hefti F. Problematik und Komplikationen der Beinver-längerungen mit dem Wagner Apparat. Orthopdde 1992;21:221-9.

11. Hood RW, Riseborough EJ. Lengthening of the lower extremity by the Wagner method. J Bone Joint Surg Am 1981;63:112.

12. Ilizarov GA, Trohova VG. Operative elongation of the femur. Ortop Traumatol Protez 1973;34:51-5.

13. Kawamura B, Hosono S, Takahashi T, Yano T, Kobayashi Y. Limb lengthening by means of subcutaneous osteotomy. J Bone Joint Surg Am 1968;50:851-65.

14. Kojimoto H, Yasui N, Goto T, Matsuda S, Shimomura Y. Bone lengthening in rabbits by callus distraction. The role of periosteum and endosteum. J Bone Joint Surg Br 1988;70:543-549.

15. Kornizek K, Tepic S, Penen SM. Limb lengthening and three-dimensional deformity corrections. A retrospective clinical study. Arch Orthop Trauma Surg 1990;109:334-40.

16. Lascombes P, Membre H, Prevot J, Barrat E. Histomorphometrie du regenerat osseaux dans les allongements des membres selon la technique d'Ilizarov. Res, Chir Orthop 1991;77:141-50.

17. Lokietek W, Legaye J, Lokietek JC. Contributing factors for osteogenesis in children's limb lengthening. J Pediatr Orthop 1991; 11:452-8.

18. Maffulli N, Hughes T, Fixsen JA. Ultrasonographic monitoring of limb lengthening. J Bone Joint Surg Br 1992;74:130-2.

19. Monticelli G, Spinelli R. Leg lengthening by closed metaphyseal corticotomy. G Ira Ortop Traum 1983;9:139-52.

20. Mosca V, Moseley CF. Complications of Wagner leg lengthening and their avoidance. Orthop Trans 1986;10:462-7.

21. Osterman K, Merikanto J. Diaphyseal bone lengthening in children using Wagner device: Long-term results. J Pediatr Orthop 1991; 11:449-51.

22. Paley D. Problems, obstacles and complications of limb lengthening by the Ilizarov technique. Clin Orthop 1990;250:81-104.

23. Schwartsman V, Schwartsman R. Corticotomy. Clin Orthop 1992; 280:37-47.

24. Vade A, Eissenstat R. Radiographic features of bone lengthening procedures. Radiology 1990;174:531-7.

25. Yasui N, Kojimoto H, Sasaki K, Shimizu H, Shimomura Y. Factors affecting callus distraction in limb lengthening. Clin Orthop 1993;293:55-60.

26. Young JWR, Kostrubiak IS, Resnik CS, Paley D. Sonographic evaluation of bone production at the distraction site in Ilizarov limb lengthening procedures. Am J Roentg 1990;154:125-8. 


\begin{tabular}{|l|c|c|}
\hline \multicolumn{3}{|c|}{ Table 1. Global characteristics } \\
\hline & Patients & Segments \\
\hline Number & 55 & 126 \\
\hline Sex & 31 & 54 \\
\hline Male & 24 & 72 \\
\hline Female & 12.5 & \\
\hline Mean age (years) & & \\
\hline Etiology & 33 & 100 \\
\hline Symmetric & 19 & 72 \\
\hline Displastic & 14 & 28 \\
\hline Not displastic & 22 & 26 \\
\hline Asymmetric & & 19 \\
\hline Congenital & & 7 \\
\hline Not congenital & & \\
\hline Segments & & 60 \\
\hline Femur & 54 & \\
\hline Tibia & & 12 \\
\hline Humerus & & \\
\hline Osteotomy level & & 88 \\
\hline Metaphyseal-proximal & & 15 \\
\hline Diaphyseal & & \\
\hline Metaphyseal-distal & & 15 \\
\hline
\end{tabular}

\begin{tabular}{|l|c|c|c|c|c|c|}
\hline \multicolumn{7}{|c|}{ Table 2. Frequency of bone lengthening formation types } \\
in three different stages \\
\hline & \multicolumn{2}{|c|}{ First control } & \multicolumn{2}{c|}{$\begin{array}{c}\text { End of } \\
\text { distraction }\end{array}$} & \multicolumn{2}{c|}{$\begin{array}{c}\text { End of } \\
\text { treatment }\end{array}$} \\
\cline { 2 - 8 } & $\mathbf{n}$ & $\mathbf{\%}$ & $\mathbf{n}$ & $\mathbf{\%}$ & $\mathbf{n}$ & $\%$ \\
\hline Major-no band & 2 & 1.6 & - & - & 3 & 2.6 \\
\hline Major-central band & 3 & 2.4 & 6 & 4.8 & 4 & 3.4 \\
\hline Similar-no band & 50 & 39.6 & 31 & 26.1 & 69 & 59.0 \\
\hline Similar-central band & 10 & 7.9 & 31 & 24.6 & 21 & 17.9 \\
\hline Similar-band & - & - & 16 & 12.7 & 11 & 9.4 \\
\hline "C"-no band & 28 & 22.1 & 18 & 14.3 & 4 & 3.4 \\
\hline "C"-central band & 1 & 0.8 & 3 & 2.4 & 1 & 0.8 \\
\hline Poor-no band & 6 & 4.8 & 5 & 4.0 & 4 & 3.4 \\
\hline Poor-central band & - & - & 4 & 3.2 & - & - \\
\hline Atrophic-no band & 26 & 20.6 & 10 & 7.9 & - & - \\
\hline
\end{tabular}


Table 3. Radiologic evolution of the bone lengthening formation

\begin{tabular}{|c|c|c|c|c|c|c|}
\hline \multirow{2}{*}{} & \multicolumn{2}{|c|}{ First control } & \multicolumn{2}{c|}{$\begin{array}{c}\text { End of } \\
\text { lengthening }\end{array}$} & \multicolumn{2}{c|}{$\begin{array}{c}\text { End of } \\
\text { treatment }\end{array}$} \\
\cline { 2 - 7 } & $\mathbf{n}$ & $\mathbf{\%}$ & $\mathbf{n}$ & $\mathbf{\%}$ & $\mathbf{n}$ & $\mathbf{\%}$ \\
\hline Transversal diameter & & & & & & \\
\hline Major & 5 & 4.0 & 6 & 4.7 & 7 & 6.0 \\
\hline Similar & 60 & 47.7 & 80 & 63.5 & 101 & 86.3 \\
\hline "C" callus & 29 & 23.0 & 21 & 16.7 & 5 & 4.2 \\
\hline Poor callus & 6 & 4.7 & 9 & 7.1 & 4 & 3.5 \\
\hline Atrophic & 26 & 20.6 & 10 & 8.0 & - & - \\
\hline Hypodense arcas & & & & & & \\
\hline No band & 110 & 87.3 & 65 & 51.6 & 80 & 68.3 \\
\hline Central band & 8 & 6.3 & 43 & 34.1 & 26 & 22.2 \\
\hline Proximal \& distal band & - & - & 5 & 4.0 & - & - \\
\hline Proximal band & - & - & 2 & 1.6 & 2 & 1.8 \\
\hline Distal band & 2 & 1.6 & 7 & 5.6 & 9 & 7.7 \\
\hline Central \& distal band & 6 & 4.8 & 4 & 3.1 & - & - \\
\hline
\end{tabular}

Table 4. Transversal diameter and bands of the bone lengthening formation in relation with the percentage of lengthening, age, and etiology at the end of the treatment

\begin{tabular}{|c|c|c|c|c|c|c|}
\hline & \multirow{3}{*}{$\begin{array}{c}\text { Lengthening } \\
\text { (\%) }\end{array}$} & \multirow{3}{*}{$\begin{array}{c}\text { Age } \\
\text { (years) }\end{array}$} & \multicolumn{4}{|c|}{ Etiology } \\
\hline & & & \multicolumn{2}{|c|}{ Symmetric } & \multicolumn{2}{|c|}{ Asymetric } \\
\hline & & & $\begin{array}{c}\text { Displastic } \\
(\%)\end{array}$ & $\begin{array}{c}\text { No displastic } \\
(\%)\end{array}$ & $\begin{array}{c}\text { Congenital } \\
(\%)\end{array}$ & $\begin{array}{c}\text { No congenital } \\
(\%)\end{array}$ \\
\hline Major & 24.7 & 9.8 & 4.1 & 0 & 0 & 42.9 \\
\hline Similar & 22.6 & 12.7 & 72.2 & 67.9 & 36.9 & 28.6 \\
\hline "C" & 22.7 & 12.0 & 9.8 & 10.8 & 47.3 & 28.5 \\
\hline Poor & 29.6 & 8.1 & 11.1 & $\mathrm{O}$ & 5.2 & 0 \\
\hline Atrophic & 14.4 & 17.6 & 2.8 & 21.4 & 10.6 & 0 \\
\hline No band & 52.3 & 13.0 & 74.2 & 63.9 & 66.7 & 28.6 \\
\hline Central band & 33.6 & 10.9 & 15.8 & 63.9 & 66.7 & 28.7 \\
\hline Proximal band & 30 & 18.0 & 0 & 9 & 0 & 0 \\
\hline Distal band & 62 & 12.0 & 10 & 9 & 0 & 0 \\
\hline
\end{tabular}




\begin{tabular}{|c|c|c|c|c|c|}
\hline & Number & $\begin{array}{c}\text { Major } \\
(\%)\end{array}$ & $\begin{array}{c}\text { Similar } \\
(\%)\end{array}$ & $\begin{array}{l}\text { "C" } \\
(\%)\end{array}$ & $\begin{array}{c}\text { Poor } \\
(\%)\end{array}$ \\
\hline Proximal metaphysis & 82 & 4.9 & 91.4 & 3.7 & 0 \\
\hline Diaphysis & 21 & 9.5 & 66.7 & 4.8 & 19 \\
\hline Distal metaphysis & 14 & 7.1 & 85.8 & 7.1 & 0 \\
\hline
\end{tabular}

\begin{tabular}{|c|c|c|c|c|c|c|}
\hline \multicolumn{7}{|c|}{$\begin{array}{l}\text { Table 6. Complications in three different stages: first control, } \\
\text { end of lengthening, and end of treatment }\end{array}$} \\
\hline & \multicolumn{2}{|c|}{ First check } & \multicolumn{2}{|c|}{ End distraction } & \multicolumn{2}{|c|}{ End treatment } \\
\hline & $\mathbf{n}$ & $\%$ & $\mathbf{n}$ & $\%$ & $\mathbf{n}$ & $\%$ \\
\hline No complications & 103 & 83.2 & 92 & 72.2 & 85 & 72.5 \\
\hline Angulation & 20 & 15.9 & 23 & 18.2 & 6 & 5.1 \\
\hline Early consolidation & 2 & 1.9 & 0 & 0 & 0 & 0 \\
\hline Delayed consolidation & 0 & 0 & 12 & 9.6 & 0 & 0 \\
\hline Fracture & 0 & 0 & 0 & 0 & 26 & 22.4 \\
\hline
\end{tabular}



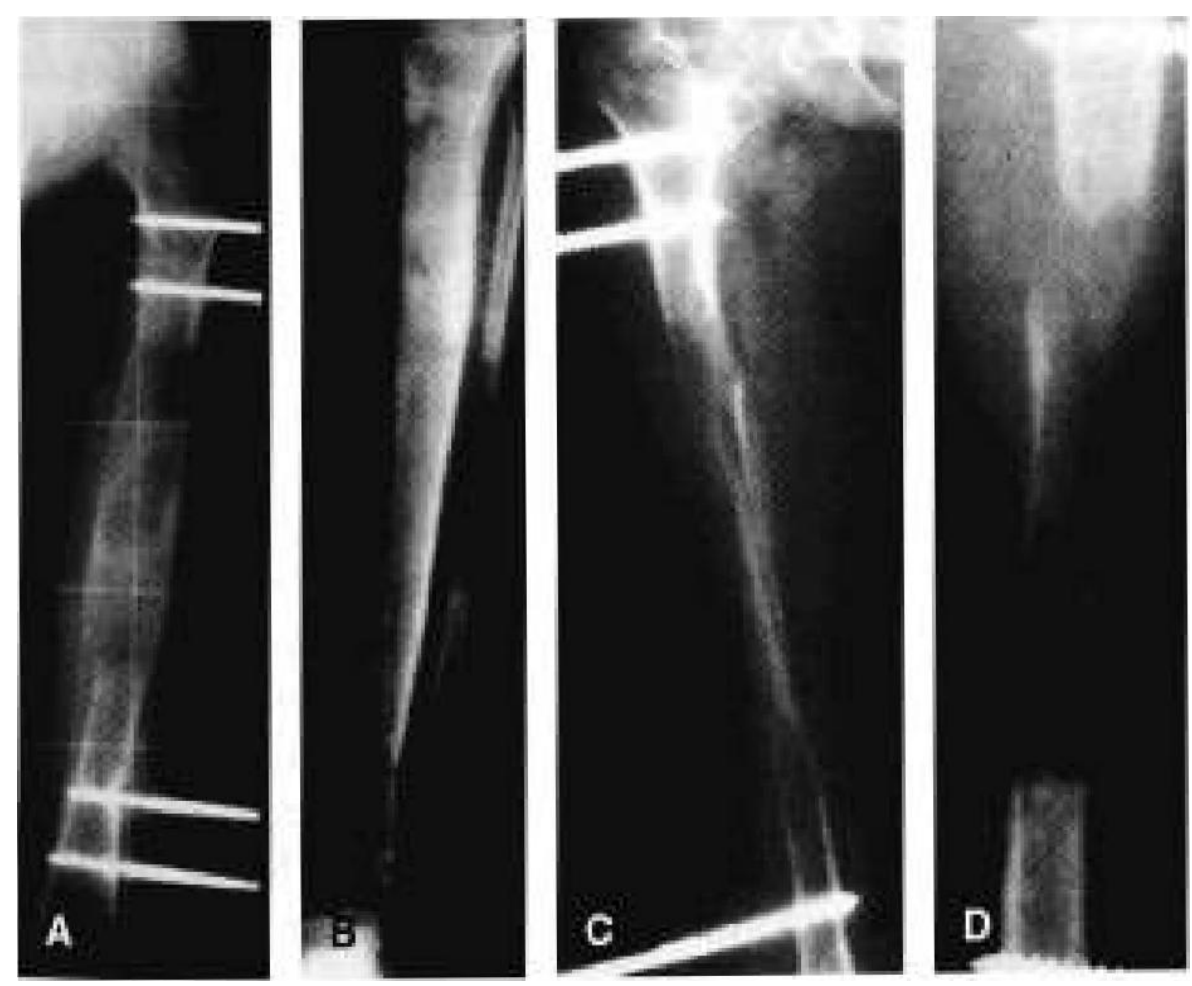

Figure 1. Anterior $(\mathbf{A}, \mathbf{C})$ and lateral $(\mathbf{B}, \mathbf{D})$ radiographs of a patient. The transverse diameter can be classified as major (broader than the original bone); similar or homogenous (same width as the original bone); or poor or narrower (less than one third of the original bone).
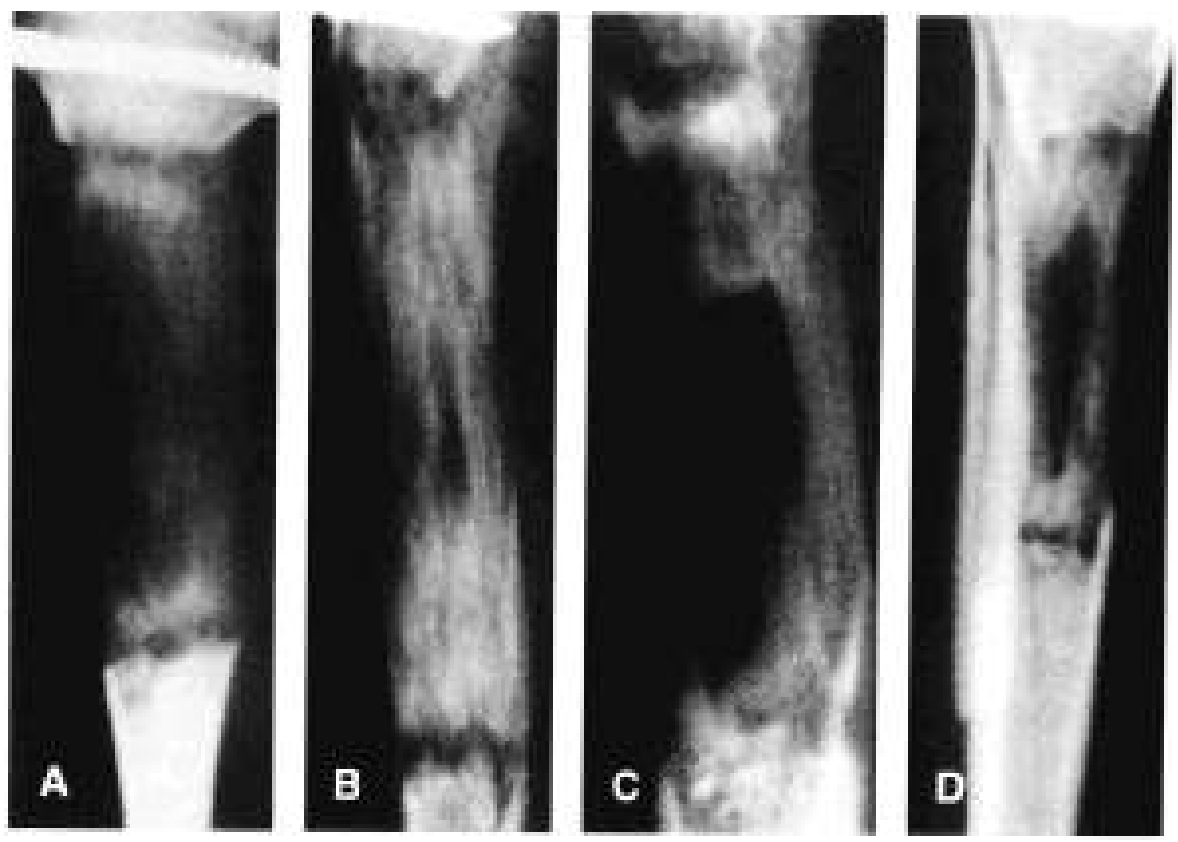

Figure 2. Anterior $(\mathbf{A}, \mathbf{C})$ and lateral $(\mathbf{B}, \mathbf{D})$ radiographs of a patient. The classification of hypodense areas or bands depends on their location in the bone formation: central, proximal or distal. 